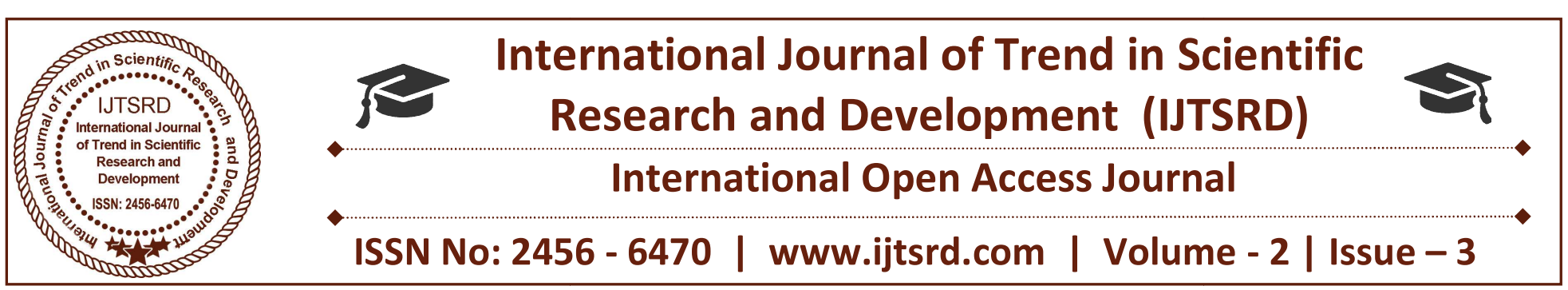

\title{
General Awareness, Perceptions and Preferences of Household Elderly Members about Diseases and Seeking Treatment in Urban Punjab
}

\author{
Ms. Jagpreet Kaur \\ Ph.D. Scholar, Department of Economics, \\ Punjabi University, Patiala, Punjab, India
}

\author{
Dr. Sukhwinder Singh \\ Professor of Economics, Centre for Research in \\ Economic Change, Punjabi University, \\ Patiala, Punjab, India
}

\section{ABSTRACT}

In the medical theory, the general awareness and perception of symptoms or diseases are the important factors to determine the utilization of health services, if any of the family members suffers from these symptoms and diseases. This research paper highlighted that regular health check-ups and tests can help to detect health problems before these problems become serious in nature. These check-ups and tests also can help to find illness early when one's chances for getting treatment and cure are better. As expected, a very tiny proportion of sampled households' elderly members went for voluntary health check-up. Physical activity (exercise) can help older people to maintain independence, recovery from illness and reduce their risk of disease. For elderly people, walking, swimming, cycling and yoga are all good forms of exercise. The data concluded that more than one-fourth of elderly members did a physical activity.

KEYWORDS: Awareness, perceptions, elderly members, diseases and seeking treatment

\section{INTRODUCTION}

As a person ages, his/her body undergoes various changes gradually or fastly. Every single cell in the body undergoes this change, but rate of change various from person to person. As the world's population ages and people live longer, it is becoming increasingly important to ensure that older people enjoy a good quality of life and experience. Satisfaction with life and general to well-being in the old age constitutes one of the major concerns for the elderly people (Priyanka, 2010 [1]). Ageing is a natural process, which presents a unique challenge for all sections of the society. Although the exact definition of elderly age group is controversial, it is generally defined as the person with a chronological age of 65 years and above (WHO, 2013 [2]).With gradual improvement in health care delivery services, life expectancy has increased and thus the percentage of the elderly population also rose.

This paper focuses on the general awareness, perceptions and preferences of elderly members about diseases and health care treatment. This paper has been divided into six sections. Section I deals with data sources and methodology of study. Section II deals with the preventive steps, if any, preferred by the elderly member. Section III examines the current health care system and proper health care for elderly. Section IV examines the role of family in health care for elderly. Section V deals with general awareness and perception of households. Section VI examines the summary of main conclusion of study.

\section{Section-I}

\subsection{Data Sources and Methodology of Study}

This study is largely based upon the primary data. The primary data have been generated through a comprehensive sample survey of 300 urban households of nine cities, namely, Patiala, Nabha and 
Rajpura (Patiala district), Ludhiana, Doraha and Payal (Ludhiana district) and Bathinda, Rampura-Phul and Bhucho Mandi (Bathinda district) selected through stratified random sampling method and through a well-structured questionnaire (Kaur, 2018[3]). The study has taken household rather than individual as the basic unit of analysis. All these households were classified into three categories of households, i.e., high status households (84), medium status households (113) and low status households (103) by assigned the quantitative scores as per the standard methodology developed by Kuppuswamy (2014[4]) for the educational level of household head and occupational status of household and for per month per capita consumption expenditure of the household by Raveendran (2008 [5]). The analysis has been carried out these three categories of households.

\section{Section II}

\subsection{Preventive Measures}

Healthy life styles in elderly are described as a lifelong process optimizing opportunities for improving and preserving health, physical, social and mental wellness; independence; quality of life; and enhancing successful life-course transitions (Burnner, 2005 [6]). For achieving such kind of healthy life, regular health examination and tests can help to find health problems before they start. Such test can also help to detect health problems early when one's chances for getting treatment and cure are better. In this way, the basic purpose of health check-up is to detect those hidden symptoms which may later cause an illness or disease. Thus, an early detection can prevent the occurrence of illness/disease. The preventive health measures are one of the most important aspects of health care services in India, but it is mostly ignored even in the urban setting, where a visit to a doctor/clinic is considered to be an unusual step when a person is maintaining normal health. Thus, the people living in urban areas of India are not prevention oriented compared to the people of western countries. However, some of the urban households often realize the need for these services and utilize them also. For this purpose, only aspects of the primary prevention that is the health check-up has been analyzed.

In the health check-up, a person's health condition has been examined through the different diagnostic techniques. As expected, a very tiny proportion of sampled household's elderly members (17.03 percent) went for voluntary health check-up. All these persons were from the high status and medium status, none of the elderly person from the low status had preferred this facility. Further, 26.15 percent and 23.13 percent of elderly person in the high status and medium household went for health check-up. A detailed scrutiny of the data further revealed that all those persons who went for health check-up were either employed in service or students (Table 1.1).

\section{Table 1.1: Distribution of Elderly Members Utilized Health Check-up}

\begin{tabular}{|l|c|c|c|}
\hline \multirow{2}{*}{ Household Status } & \multicolumn{3}{|c|}{ Health Check-Up } \\
\cline { 2 - 4 } & Yes & No & Total \\
\hline Low & 0 & 127 & 127 \\
\hline \% & 0.00 & 100.00 & 100.00 \\
\hline Medium & 37 & 123 & 160 \\
\hline \% & 23.13 & 76.88 & 100.00 \\
\hline High & 34 & 96 & 130 \\
\hline \% & 26.15 & 73.85 & 100.00 \\
\hline Total & 71 & 346 & 417 \\
\hline \% J Ournal & 17.03 & 82.97 & 100.00 \\
\hline
\end{tabular}

Source: Primary Survey.

The household heads were asked to state reason/s for not using health check-up to prevent the occurrence of diseases. An assessment of reasons behind this phenomenon had been reproduced in the Table 1.2. The data concluded that 51.05 percent of households reported uselessness as the main reason for not preferring health check-up. Another one-fifth of households (19.71 percent) stated that no government facility was available for check-up and 17.61 percent of the households stated the poor economic conditions as the main reason behind not going for health checkup. Interestingly, 30.65 percent of low status households mentioned the poor economic conditions as the main reason. And, another 17.74 percent of low status households reported non-availability of government facility near their homes. Further, many households also gave more than one reason (Table 1.2). 
International Journal of Trend in Scientific Research and Development (IJTSRD) ISSN: 2456-6470

\section{Table 1.2: Distribution of Elderly Patients Not Preferring Health Check-Up by Reasons}

\begin{tabular}{|l|c|c|c|c|}
\hline \multirow{2}{*}{ Reasons } & \multicolumn{4}{|c|}{ Household Status } \\
\cline { 2 - 5 } & Low & Medium & High & Total \\
\hline Useless & 115 & 116 & 85 & 316 \\
\hline \% & 37.10 & 59.79 & 73.91 & 51.05 \\
\hline Expensive & 45 & 22 & 5 & 72 \\
\hline \% & 14.52 & 11.34 & 4.35 & 11.63 \\
\hline $\begin{array}{l}\text { Poor Economic } \\
\text { Condition }\end{array}$ & 95 & 14 & 0 & 109 \\
\hline \% & 30.65 & 7.22 & 0.00 & 17.61 \\
\hline $\begin{array}{l}\text { No Govt. } \\
\text { Facility }\end{array}$ & 55 & 42 & 25 & 122 \\
\hline \% & 17.74 & 21.65 & 21.74 & 19.71 \\
\hline All Reasons & 310 & 194 & 115 & 619 \\
\hline \% & 100.00 & 100.00 & 100.00 & 100.00 \\
\hline
\end{tabular}

Note: Many patients reported multiple reasons

Source: Primary Survey.

It is well established that physical activity is essential for maintaining physical abilities and independence in older age. Regular physical activity is important contribute or to good overall health, including promotion healthy weight and reducing NCDs risk (Nelson, et al., 2007 [7]). Physical activity can also maintain to improve brain health. Observational studies have demonstrated that being physically active is associated with lower a lower risk of cognitive decline and dementia (Parker, et al., 2012 [8]). There is growing evidence that physical activity has positive effect on cognitive function for older adults with healthy cognition mild impair and dementia (Lautenschlager, et al., 2008 [9]). Generally, there is a direct relationship between physical activity and high level of education, considering the physical activity components of a healthy lifestyle, higher awareness in people with higher education is justifiable (Lee, et al., 2005 [10]). Physical activity (exercise) can help older people to maintain independence, recover from the illness at the early stage and reduce their risk of getting disease. Walking, swimming and cycling are all good forms of exercise. Table 1.3 highlights the information on physical activity of elderly people. The data concluded that only 27.82 percent elderly members do physical activity and 72.18 do not take any physical exercise. (Table 1.3)
Table 1.3: Distribution of Elderly Members by Information on Physical Activity

\begin{tabular}{|l|c|c|c|}
\hline \multirow{2}{*}{ Household Status } & \multicolumn{3}{|c|}{ Physical Activity } \\
\cline { 2 - 4 } & Yes & No & Total \\
\hline \% & 20 & 107 & 127 \\
\hline Medium & 15.75 & 84.25 & 100.00 \\
\hline \% & 54 & 106 & 160 \\
\hline High & 33.75 & 66.25 & 100.00 \\
\hline \% & 42 & 88 & 130 \\
\hline Total & 32.31 & 67.69 & 100.00 \\
\hline \% & 116 & 301 & 417 \\
\hline Source & 27.82 & 72.18 & 100.00 \\
\hline
\end{tabular}

Source: Primary Survey

Table 1.4 highlighted the comparisons of different types of physical activities. Main physical activities were walking (47.41 percent), cycling (30.17 percent), swimming (5.17 percent) and others it includes yoga and combination of two or more type of exercises (17.24 percent). In low status more than half (55.00 percent) of elderly were did walking, 25.00 percent were did other exercises. In medium status and high status 40.74 percent and 52.38 percent did walking, 37.03 percent and 26.19 percent did cycling and 18.51 percent and 11.90 percent did other exercises as physical activities respectively.

Table 1.4: Distribution of Elderly Members by Type of Physical Activity

\begin{tabular}{|l|c|c|c|c|}
\hline \multirow{2}{*}{$\begin{array}{c}\text { Type of Physical } \\
\text { Activity }\end{array}$} & \multicolumn{3}{c|}{ Household Status } & \\
\cline { 2 - 5 } Walking & Low & Medium & High & Total \\
\hline \% & 11 & 22 & 22 & 55 \\
\hline Swimming & 55.00 & 40.74 & 52.38 & 47.41 \\
\hline \% & 0 & 2 & 4 & 6 \\
\hline Cycling & 0.00 & 3.70 & 9.52 & 5.17 \\
\hline \% & 4 & 20 & 11 & 35 \\
\hline Others & 20.00 & 37.03 & 26.19 & 30.17 \\
\hline \% & 5 & 10 & 5 & 20 \\
\hline Total & 25.00 & 18.51 & 11.90 & 17.24 \\
\hline$\%$ & 20 & 54 & 42 & 116 \\
\hline
\end{tabular}

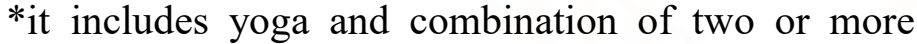
types of exercises. Source: Primary Survey.

\section{Section: III}

\subsection{Health Care System}

WHO (2004 [11]), study on the global health care profile ranked India's health care system at $112^{\text {th }}$ out of 190 countries. This survey highlighted three major health concerns for India that still are prominent today. According to WHO, (2005 [12]) the first 
concern was the high vulnerability of young children. Among children under five, 43.5 percent are underweight (the highest percentage in the world) and have 6.6 percent dying before their fifth birthday (which is quite high compared to United States' rate of 0.8 percent). The second major concern is poor sanitation. Only about 30 percent of the population uses improved sanitation facilities and this figure dips below 20 percent when focusing solely on the rural population. The final concern is disease. The top three are malaria, tuberculosis, and diarrhea. Combined, these health concerns have hindered India's life expectancy: 63 for males and 66 for females.

\section{Table 1.4 : Distribution of Elderly People by Difficulty in Getting Proper Health Care}

\begin{tabular}{|l|c|c|c|}
\hline \multirow{2}{*}{ Household Status } & \multicolumn{3}{|c|}{ Difficulty in Getting Health Care } \\
\cline { 2 - 4 } & Yes & No & Total \\
\hline \%ow & 122 & 5 & 127 \\
\hline Medium & 96.06 & 3.94 & 100.00 \\
\hline \% & 51 & 109 & 160 \\
\hline High & 31.88 & 68.13 & 100.00 \\
\hline \% & 12 & 118 & 130 \\
\hline Total & 9.23 & 90.77 & 100.00 \\
\hline \% & 185 & 232 & 417 \\
\hline Source Pring & 44.36 & 55.64 & 100.00 \\
\hline
\end{tabular}

Source: Primary Survey

The analysis of data on difficulty in proper health care for elderly revealed that 44.36 percent of elderly mentioned difficulty in getting health care and 55.64 percent have not faced any difficulty. The information in Table 1.4 proved that, on whole low status households face more difficulty (96.06 percent) as compared to the medium status (31.88 percent) and the high status (9.23 percent) (Table 1.4). Table 1.5 depicts household elderly members' satisfaction for current health care system 34.05 percent household were dissatisfied from current health care system. Further, dissatisfaction proportion was more in the low status (90.55 percent) as compared to the medium status (11.88 percent) and the high status (6.15 percent).

\section{Table 1.5: Distribution of Elderly by Satisfaction of Current Health Care System}

\begin{tabular}{|l|c|c|c|c|}
\hline \multirow{2}{*}{ Satisfaction } & \multicolumn{3}{|c|}{ Household Status } & \\
\cline { 2 - 5 } & Low & Medium & High & Total \\
\hline Satisfied & 0 & 75 & 65 & 140 \\
\hline \% & 0.00 & 46.88 & 50.00 & 33.57 \\
\hline Dissatisfy & 115 & 19 & 8 & 142 \\
\hline \% & 90.55 & 11.88 & 6.15 & 34.05 \\
\hline Neutral & 5 & 56 & 45 & 106 \\
\hline \% & 3.94 & 35.00 & 34.62 & 25.42 \\
\hline Donot Know & 7 & 10 & 12 & 29 \\
\hline \% & 5.51 & 6.25 & 9.23 & 6.95 \\
\hline Total & 127 & 160 & 130 & 417 \\
\hline \% & 100.00 & 100.00 & 100.00 & 100.00 \\
\hline
\end{tabular}

Source: Primary Survey

The data also shows 33.57 percent elderly satisfied from current health care system. In which 50 percent are from high and 46.88 percent are from medium status elderly members. 25.42 percent elderly are neutral from current health care system. The main reason for dissatisfaction in the low status elderly is costly treatment in private hospitals and the benefits of super specialty have not reached the poor at all. Factors such as elite orientation of the management, lack of awareness among the poor people for free treatment and ineffective mechanisms. Table 1.6 shows the elderly members' preferences on type of treatment. An analysis of data showed 53.24 percent of elderly preferred allopathic system of treatment whereas 12.71 percent homeopathic and 23.74 percent ayurvedic and rest 10.31 percent prefer any other (it includes home remedies and combination of two medicines). The main reason of preferring allopathic is fast recovery and easy availability.

Table 1.6: Distribution of Households by Type of Treatment

\begin{tabular}{|c|c|c|c|c|c|}
\hline \multirow[t]{2}{*}{ Household Status } & \multicolumn{4}{|c|}{ Type of Treatment } & \multirow[b]{2}{*}{ Total } \\
\hline & Allopathic & Homeopathic & Ayurvedic & Any other* & \\
\hline Low & 61 & 5 & 28 & 33 & 127 \\
\hline$\%$ & 48.03 & 0.00 & 22.05 & 25.98 & 100.00 \\
\hline Medium & 75 & 33 & 42 & 10 & 160 \\
\hline$\%$ & 46.88 & 20.63 & 26.25 & 6.25 & 100.00 \\
\hline High & 86 & 15 & 29 & 0 & 130 \\
\hline$\%$ & 66.15 & 11.54 & 22.31 & 0.00 & 100.00 \\
\hline Total & 222 & 53 & 99 & 43 & 417 \\
\hline$\%$ & 53.24 & 12.71 & 23.74 & 10.31 & 100.00 \\
\hline
\end{tabular}

*it includes home remedies and combination of two medicines. Source: Primary Survey 
Table 1.7: Distribution of Households for Changes in Healthcare System

\begin{tabular}{|l|c|c|c|c|}
\hline \multirow{2}{*}{ Household } & \multicolumn{4}{|c|}{ Changes } \\
\cline { 2 - 5 } Status & A & B & C & Total \\
\hline \%ow & 64 & 36 & 27 & 127 \\
\hline Medium & 50.39 & 28.35 & 21.26 & 100.00 \\
\hline \% & 76 & 54 & 30 & 160 \\
\hline High & 47.50 & 33.75 & 18.75 & 100.00 \\
\hline \% & 29 & 67 & 34 & 130 \\
\hline Total & 22.31 & 51.54 & 26.15 & 100.00 \\
\hline \% & 169 & 157 & 91 & 417 \\
\hline
\end{tabular}

a- free medical facility, b- multispecialty hospital, cHealth Insurance. Source: Primary Survey

Table 1.7 shows the changes in health care system. Data shows major changes should be free medical facility, multispecialty hospital and health insurance. The data revealed that 40.53 percent of elderly wants free medical facility, 37.65 needs multispecialty hospital and 21.82 percent needs health insurance for elderly people. In low status 50.39 percent, medium 47.50 percent and 22.31 percent in the high status elderly preferred free medical facility as the changes in the health care system, other changes in health care system are multispecialty hospital and health insurance 51.54 percent of elderly in high status, 33.75 percent in medium status and 28.35 percent in low status wants multispecialty hospital as a change in health care system. 21.82 percent of elderly wants health insurance scheme as a change in health care system. 26.15 percent in high status, 18.75 in the medium status and 21.26 percent in low status wants health insurance scheme for the elderly people. Thus data revealed that most of the elderly people wanted to be the free medical facility as the change in health care system.

Table 1.8: Distribution of Household for Elderly People Health Expenses

\begin{tabular}{|c|c|c|c|c|c|}
\hline \multirow{2}{*}{$\begin{array}{l}\text { Household } \\
\text { Status }\end{array}$} & \multicolumn{4}{|c|}{ Sources } & \multirow[b]{2}{*}{ Total } \\
\hline & $\mathbf{A}$ & B & $\mathrm{C}$ & D & \\
\hline Low & 45 & 9 & 15 & 58 & 127 \\
\hline$\%$ & 35.43 & 7.09 & 11.81 & 45.67 & 100.00 \\
\hline Medium & 40 & 14 & 18 & 88 & 160 \\
\hline$\%$ & 25.00 & 8.75 & 11.25 & 55.00 & 100.00 \\
\hline High & 47 & 19 & 25 & 39 & 130 \\
\hline$\%$ & 36.15 & 14.62 & 19.23 & 30.00 & 100.00 \\
\hline Total & 132 & 42 & 58 & 185 & 417 \\
\hline$\%$ & 31.65 & 10.07 & 13.91 & 44.36 & 100.00 \\
\hline
\end{tabular}

a-Own Saving ,b-Health Insurance ,c-Loan ,d-Family support. Source: Primary Survey
Table 1.8 explains in the case of health expenses elderly people are dependent upon their family members (44.36 percent), 31.65 percent household elderly spend their own saving, 13.91 percent take loan for treatment and 10.07 percent household elderly members use their health insurance. The data revealed that in the low status 45.67 percent elderly members depend on their family members, 11.81 percent on loans, 35.43 percent on their own saving and only 7.09 percent on health insurance schemes for their health expenses, In the medium status 55.00 percent elderly members depend on their family members, 25.00 percent on their own saving, 11.25 on the loan and 8.75 percent on health insurance and in the high status 36.15 percent elderly depend on their own saving, 30.00 percent on family support 19.23 percent on loan and 14.62 percent on the health insurance schemes for their health expenses. Thus data showed most of the elderly people depends on their family members for their health care expenses needs.

\section{Section IV}

\subsection{Role of Family in Health Care Utilization among Elderly}

Family is a group consisting of parents and children living together in a household and they are also depended on each other for living a good and healthy life. Health and wellbeing are the result of synergistic interactions among a variety of determinants. Family structure and composition are two important social determinants that may also affect health behaviors and outcomes. Health problems of elderly persons are supposed to be the major concern of a family as older people are more prone to suffer from ill-health than younger age group. So, family plays an important role to care the elderly population

In Indian society, one can find three types of familysingle, nuclear and joint. Nuclear family is consisting of a pair of adults and their unmarried children where as the joint family is consist of parents, their children, and the children' spouses and the off springs. The Indian family traditionally has been viewed as a close-knit social unit from which its members derived support, security, and means for meeting their needs (Chang, 1992[13]). In Indian the elderly were cared for by their families; moreover, respect for the aged was considered a virtue in the Indian tradition. The aged people also represent life experience, 
knowledge, authority, and status. In today's world, however, the emphasis on individualism, nuclear family autonomy in an urban-industrial milieu and economic discrimination elderly often create pressures on the children of Indian immigrants that lead to disregard for their elderly parents (Ghosh, 2011[14]). In recent years, as the number of elderly has increased and the influence of cultural norms and traditional structures has diminished, the problems of older Indians have multiplied (Silva, 2005 [15]). Inadequate income reduced physical capabilities, and social isolation often makes old age a period of degeneration and sufferings. The Indian elderly especially are confronted with the poverty, isolation, racial discrimination, poor housing, and poor health (Bose, 2007[16]).
Regarding the household elderly health care, most of elderly people are taken care by their spouse and sons. The data showed that in low status category, 40.94 percent of elderly persons have cared off by their sons, 9.45 percent by their daughters, 33.07 percent by their spouses and 16.54 percent by their grandchildren. The data also showed that in the medium status elderly 42.50 percent cared by their sons, 40.63 by their spouses, 5.00 percent by their daughters, 7.50 percent by their grand children and 4.38 percent by domestic helpers. On the other hand, in the high status households, 22.58 percent was looked after by their son, 30 percent by spouses, 11.54 by their daughters, 12.31 by grandchildren and 19.23 percent by domestic helpers (Table 1.9).

Table 1.9: Distribution of Elderly Members for Healthcare

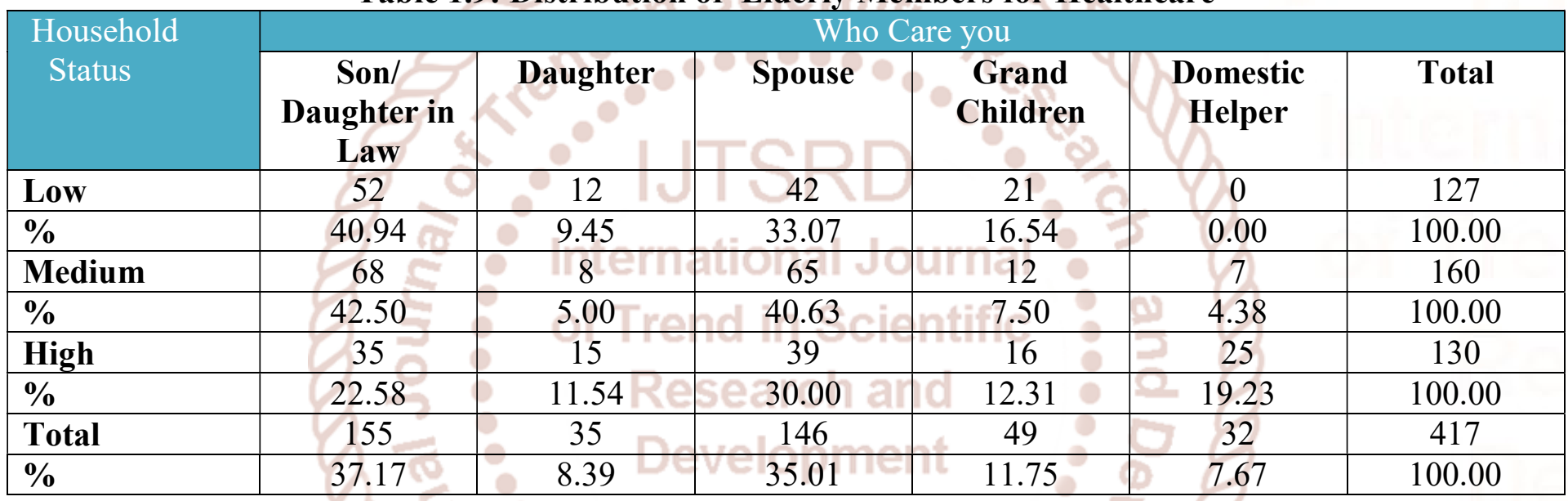

Source: Primary Survey

The data on distribution of elderly people to take health facility showed that in high status households, 22.58 percent elderly patients went with their son, 30 percent with spouse and 19.23 percent with their domestic helpers 12.31 percent by grand children. In the case of medium and low status, 42.50 percent and 40.94 percent elderly with sons, 5 percent and 9.45 percent with their daughters, 40.63 percent and 33.07 percent with their spouses, 7.50 percent and 16.54 percent with grandchildren and 4.38 percent, 0 percent with domestic helpers (Table 1.10).

Table 1.10: Distribution of Household Elderly People to Take Health Facility

\begin{tabular}{|l|c|c|c|c|c|c|}
\hline \multirow{2}{*}{ Household Status } & \multicolumn{6}{|c|}{ Who Takes to Health Facility } \\
\cline { 2 - 7 } & $\begin{array}{c}\text { Son/Daughter } \\
\text { in law }\end{array}$ & Daughter & Spouse & $\begin{array}{c}\text { Grand } \\
\text { Children }\end{array}$ & $\begin{array}{c}\text { Domestic } \\
\text { Helper }\end{array}$ & Total \\
\hline Low & 52 & 12 & 42 & 21 & 0 & 127 \\
\hline \% & 40.94 & 9.45 & 33.07 & 16.54 & 0.00 & 100.00 \\
\hline Medium & 68 & 8 & 65 & 12 & 7 & 160 \\
\hline $\mathbf{\%}$ & 42.50 & 5.00 & 40.63 & 7.50 & 4.38 & 100.00 \\
\hline High & 35 & 15 & 39 & 16 & 25 & 130 \\
\hline$\%$ & 22.58 & 11.54 & 30.00 & 12.31 & 19.23 & 100.00 \\
\hline Total & 155 & 35 & 146 & 49 & 32 & 417 \\
\hline$\%$ & 37.17 & 8.39 & 35.01 & 11.75 & 7.67 & 100.00 \\
\hline
\end{tabular}

Source: Primary Survey. 
Table 1.11 explains that regarding the daily health care most of elderly was cared by their spouse $(40.29$ percent and son/daughter in law (35.97 percent). The data also explained that in the low status 51.18 percent elderly members were cared by their spouse, 6.30 percent by their daughters, 36.22 percent by their son /daughter in law and 6.30 percent by their grandchildren. In the case of high and medium status
30.77 percent and 39.38 percent by their spouses, 9.23 percent and 8.75 percent cared by their daughters, 36.92 percent and 35.00 percent by their son/ daughter in law, 6.92 percent and 9.38 percent by grandchildren and 16.15 percent and 7.50 percent by domestic helpers.

Table 1.11: Distribution of Elderly Members by Daily Health Care

\begin{tabular}{|c|c|c|c|c|c|c|}
\hline \multirow[t]{2}{*}{ Household Status } & \multicolumn{6}{|c|}{ Daily Health Care by Family Members } \\
\hline & Spouse & Daughter & $\begin{array}{l}\text { Son/Daughter } \\
\text { in Law }\end{array}$ & $\begin{array}{l}\text { Grand } \\
\text { Children }\end{array}$ & $\begin{array}{l}\text { Domestic } \\
\text { Helper }\end{array}$ & Total \\
\hline Low & 65 & 8 & 46 & 8 & 0 & 127 \\
\hline$\%$ & 51.18 & 6.30 & 36.22 & 6.30 & 0.00 & 100.00 \\
\hline Medium & 63 & 14 & 56 & 15 & 12 & 160 \\
\hline$\%$ & 39.38 & 8.75 & $\mathrm{C}=35.00$ & 9.38 & 7.50 & 100.00 \\
\hline High & 40 & 12111 & 48 & 9 & 21 & 130 \\
\hline$\%$ & 30.77 & 9.23 & 36.92 & 6.92 & 16.15 & 100.00 \\
\hline Total & 168 & 34 & 150 & 32 & 33 & 417 \\
\hline$\%$ & 40.29 & 8.15 & -35.97 & 7.67 & 7.91 & 100.00 \\
\hline
\end{tabular}

Source: Primary Survey.

\section{Section V}

\subsection{General Awareness and Perceptions}

In the medical theory, the general awareness and perception of symptoms or diseases are the important factors to determine the utilization of healthcare services, if any of the family members suffers from these symptoms and diseases. The poor awareness and perceptions indicate lack of knowledge about the scientific way to treat the diseases. Moreover, the poor perception of symptoms and diseases may produce a communication gap between the patient and the doctor because the patient's presentation of his/her health problems to the doctor depends, in the first instance, on the patient's perceptions (Logan, 1996 [17]). Hence, it is interesting to examine the awareness and perceptions of non-communicable /communicable diseases and treatment across different categories of households. Early diagnosis has always a better chance for cure, prevention of the diseases and delays its complications. Physical health assessments can help to identify early sign and symptoms of undiagnosed cases of physical health problems in the elderly (Reji and Kaur, 2015 [18]).

The analysis of data on main causes of diseases revealed that 23.26 percent of household heads mentioned the main reasons behind their illness were old age, followed by the Pollution (22.29 percent), the God's curse (19.38 percent), germs (15.24 percent). The poor nutritional level as the cause of diseases was mentioned by 12.95 percent of households. Further, it came to light that the high status households mentioned the scientific causes, i.e., 32.39 percent of them reported ageing as the main reason and 23.58 percent mentioned the germs as the reason. In the low status households, the main cause of diseases was stated as the God's curse (32.13 percent) and the poor nutritional level (24.46 percent). In the medium status households 26.00 percent mentioned pollution, 24.00 percent reported old age, 15.00 percent mentioned God's curse and 20.75 percent germs. A very small proportion of household heads (6.87 percent) mentioned other causes which included the religious cause as major cause of diseases (Table 1.12). 
International Journal of Trend in Scientific Research and Development (IJTSRD) ISSN: 2456-6470

Table 1.12: Distribution of Households Responses Regarding Main Causes of Diseases

\begin{tabular}{|l|c|c|c|c|}
\hline \multirow{2}{*}{ Causes } & \multicolumn{3}{|c|}{ Household Status } & \\
\cline { 2 - 5 } & Low & $\begin{array}{c}\text { Mediu } \\
\text { m }\end{array}$ & High & Total \\
\hline Germs & 15 & 83 & 75 & 173 \\
\hline \% & 3.60 & 20.75 & 23.58 & 15.24 \\
\hline Pollution & 81 & 104 & 68 & 253 \\
\hline \% & 19.42 & 26.00 & 21.38 & 22.29 \\
\hline $\begin{array}{l}\text { Poor } \\
\text { Nutritional } \\
\text { Level }\end{array}$ & 102 & 22 & 23 & 147 \\
\hline \% & & & & \\
\hline Old Age & 65 & 96 & 103 & 264 \\
\hline$\%$ & 15.59 & 24.00 & 32.39 & 23.26 \\
\hline God Curse & 134 & 60 & 26 & 220 \\
\hline \% & 32.13 & 15.00 & 8.18 & 19.38 \\
\hline Any other & 20 & 35 & 23 & 78 \\
\hline \% & 4.80 & 8.75 & 7.23 & 6.87 \\
\hline Total & 417 & 400 & 318 & 1135 \\
\hline$\%$ & 100 & 100 & 100 & 100 \\
\hline
\end{tabular}

Note: Many households reported multiple reasons.

Source: Primary Survey.

Further, only 14.67 percent of sampled urban households preferred to seek medical treatment if any family member reported a minor symptom/disease. And, 85.33 percent did not go for treatment for the minor symptoms. The minor diseases were the body pain, headache, toothache, giddiness, etc. However, in the high status households, 27.38 percent households preferred to get treatment for the minor symptoms also. But, in the low status and the medium status households, this proportion was very low (5.83 percent and 13.27 percent respectively) [Table 1.13].

Table 1.13: Distribution of Households Preferring Treatment for Minor Symptoms

\begin{tabular}{|l|c|c|c|}
\hline Status & Yes & No & Total \\
\hline Low & 6 & 97 & 103 \\
\hline \% & 5.83 & 94.17 & 100.00 \\
\hline Medium & 15 & 98 & 113 \\
\hline \% & 13.27 & 86.73 & 100.00 \\
\hline High & 23 & 61 & 84 \\
\hline \% & 27.38 & 72.62 & 100.00 \\
\hline Total & 44 & 256 & 300 \\
\hline \% & 14.67 & 85.33 & 100.00 \\
\hline
\end{tabular}

Source: Primary Survey.

Table 1.14 highlights the main reasons of not seeking treatment for minor symptoms. In the high status elderly main reason was they preferred home remedies (74.16 percent) for minor diseases, 22.47 percent elderly gives loss of working day and 3.37 percent elderly gives costly as the reason for not taking treatment for the minor diseases. In the medium status and low status 57.63 percent and 26.07 percent elderly preferred home remedies for minor diseases, 16.95 percent and 25.12 percent elderly gives loss of working day as the reason for not taking treatment. Other reason for not taking treatment is the costly treatment as main reasons for not taking treatment for minor diseases.

\begin{tabular}{|c|c|c|c|c|}
\hline \multirow[t]{2}{*}{ Reasons } & \multicolumn{4}{|c|}{ Household Status } \\
\hline & Low & Medium & High & Total \\
\hline $\begin{array}{l}\text { Preferring } \\
\text { Home Medicine }\end{array}$ & 56 & 68 & 66 & 189 \\
\hline 00 & 26.07 & 57.63 & 74.16 & 45.22 \\
\hline $\begin{array}{l}\text { Loss of } \\
\text { Working Days }\end{array}$ & 53 & 20 & 20 & 93 \\
\hline$\%$ & 25.12 & 16.95 & 22.47 & 22.25 \\
\hline $\begin{array}{l}\text { Costly } \\
\text { Treatment }\end{array}$ & 103 & 30 & 3 & 136 \\
\hline$\%$ & 48.82 & 25.42 & 3.37 & 32.54 \\
\hline Total $\cap 1 \mathrm{O}$ & 211 & 118 & 89 & 418 \\
\hline$\%$ & 100.00 & 100.00 & 100.00 & 100.00 \\
\hline
\end{tabular}

Note: Many household gives multiple reasons.

Source: Primary Survey.

Table 1.15: Distribution of Households Preferring Treatment for Major Symptoms

\begin{tabular}{|l|c|c|c|}
\hline Household Status & Yes & No & Total \\
\hline Low & 82 & 21 & 103 \\
\hline \% & 79.61 & 20.39 & 100.00 \\
\hline Medium & 105 & 8 & 113 \\
\hline \% & 92.92 & 7.08 & 100.00 \\
\hline High & 84 & 0 & 84 \\
\hline$\%$ & 100.00 & 0.00 & 100.00 \\
\hline Total & 271 & 29 & 300 \\
\hline \% & 90.33 & 9.67 & 100.00 \\
\hline
\end{tabular}

Source: Primary Survey.

Regarding the major symptoms/diseases table 1.15 highlighted that 90.33 percent of household heads preferred to seek treatment and 9.67 percent household heads did not preferred to seek treatment. In the high status households, 100 percent household heads got treatment for major symptoms, 92.92 percent in the medium status and 79.61 percent in the 
low status households. The main reasons for not seeking treatment for major symptoms diseases were the home medicine (51.72 percent), followed by costly treatment (31.03 percent) and loss of working days (17.24 percent). In high status category, 100 percent of elderly members got treatment for major symptoms (Table 1.16).

Table 1.16: Distribution of Households Not Seeking Treatment for Major Symptoms/ Diseases

\begin{tabular}{|l|c|c|c|c|}
\hline \multirow{2}{*}{ Reasons } & \multicolumn{4}{c|}{ Household Status } \\
\cline { 2 - 5 } & Low & Medium & High & Total \\
\hline $\begin{array}{l}\text { Prefer Home } \\
\text { Medicine }\end{array}$ & 11 & 4 & 0 & 15 \\
\hline$\%$ & 52.38 & 50.00 & 0.00 & 51.72 \\
\hline $\begin{array}{l}\text { Loss of } \\
\text { Working Days }\end{array}$ & 3 & 2 & 0 & 5 \\
\hline$\%$ & 14.29 & 25.00 & 0.00 & 17.24 \\
\hline $\begin{array}{l}\text { Costly } \\
\text { Treatment }\end{array}$ & 7 & 2 & 0 & 9 \\
\hline$\%$ & 33.33 & 25.00 & 0.00 & 31.03 \\
\hline Total & 21 & 8 & 0 & 29 \\
\hline \% & 100.00 & 100.00 & 0.00 & 100.00 \\
\hline
\end{tabular}

Source: Primary Survey

The data on households' preferences for seeking treatment revealed that nearly two-third of household heads (66.79 percent) preferred to get treatment from the MBBS/MD doctors. In the case of high status households, 94.05 percent preferred treatment from the doctors having $\mathrm{MBBS} / \mathrm{MD}$ degree compared to 80.95 percent in the medium status households and 20.73 percent in the low status households. Indeed, it is major worry that in the low status households, 48.78 percent of patients got treatment/from the unqualified healers. (Table 1.17)

\section{Table 1.17: Distribution of Households Preferring Treatment by Doctor's Qualification}

\begin{tabular}{|l|c|c|c|c|}
\hline Qualification & Low & Medium & High & Total \\
\hline MBBS/MD & 17 & 85 & 79 & 181 \\
\hline \% & 20.73 & 80.95 & 94.05 & 66.79 \\
\hline RMP & 25 & 12 & 5 & 42 \\
\hline \% & 30.49 & 11.43 & 5.95 & 15.50 \\
\hline Others* & 40 & 8 & 0 & 48 \\
\hline$\%$ & 48.78 & 7.62 & 0.00 & 17.71 \\
\hline Total & 82 & 105 & 84 & 271 \\
\hline \% & 100.00 & 100.00 & 100.00 & 100.00 \\
\hline
\end{tabular}

*It includes Chemists, Vaid /Hakims etc.

Source: Primary Survey.
With regard to the reasons behind seeking treatment from a particular doctor/ health centre, the analysis of answers given by the household heads presented interesting facts. For instance, on the whole, 26.06 percent household heads preferred treatment from experienced doctors/centre; 14.48 percent household heads mentioned the fast recovery as the reason; 24.13 percent household heads were attracted due to good facility available in the centre/doctor; 16.41 percent household heads preferred it due to not costly/affordable treatment; and 18.92 percent households preferred the centre/doctor which was near to their homes. Across the different categories of households, the low status households preferred to get treatment either from the 'not costly/affordable treatment' (41.67 percent) or 'near to home' (34.09 percent) facility compared to other categories of households (Table 1.18).

\section{Table 1.18: Distribution of Households Seeking} Treatment From Particular Doctor/Centre by Reason

\begin{tabular}{|l|c|c|c|c|}
\hline \multirow{2}{*}{ Reasons } & \multicolumn{4}{|c|}{ Household Status } \\
\cline { 2 - 5 } & Low & $\begin{array}{c}\text { Mediu } \\
\text { m }\end{array}$ & High & Total \\
\hline $\begin{array}{l}\text { Experienced } \\
\text { Doctor }\end{array}$ & 12 & 68 & 55 & 135 \\
\hline \% & 9.09 & 28.33 & 37.67 & 26.06 \\
\hline Fast Recovery & 18 & 35 & 22 & 75 \\
\hline$\%$ & 13.64 & 14.58 & 15.07 & 14.48 \\
\hline $\begin{array}{l}\text { Nearest to } \\
\text { Home }\end{array}$ & 45 & 48 & 5 & 98 \\
\hline$\%$ & 34.09 & 20.00 & 3.42 & 18.92 \\
\hline Good Facility & 2 & 67 & 56 & 125 \\
\hline \% & 1.52 & 27.92 & 38.36 & 24.13 \\
\hline Not Costly & 55 & 22 & 8 & 85 \\
\hline$\%$ & 41.67 & 9.17 & 5.48 & 16.41 \\
\hline Total & 132 & 240 & 146 & 518 \\
\hline$\%$ & 100.00 & 100.00 & 100.00 & 100.00 \\
\hline
\end{tabular}

Note: Some households gave more than one reasons. Source: Primary Survey.

It means that the economic reasons i.e. not so costly/affordable treatment are more important, especially in the low status household heads, to understand the choices of households to seek treatment, if any member of their households suffered from NCDs and communicable diseases. Good facility and experienced doctor are more important reasons in high status and medium status households. Fast recovery also plays an important role in the selection of health centres for treatment. 


\section{Section VI}

\subsection{Summary of Main Conclusions:}

The study highlighted that regular health check-ups and tests can help to detect health problems before they start. These check-ups and test also can help to find problems early when one's chances for getting treatment and cure are better. As expected, a very tiny proportion of sampled household's elderly members went for voluntary health check-up. All these members were from the high status and medium status, none of the elderly person from low status had preferred this facility. A detailed scrutiny of the data further revealed that those who went for health checkup were either employed in service or students. The data concluded that one-half of elderly member reported uselessness as the main reason for not preferring health check-up. Another one-fifth of elderly member stated that no government facility was available for seeking health check-up and one fifth of the households stated the poor economic conditions as the main reason.

Physical activity (exercise) can help older people maintain independence, recovery from illness and reduce their risk of disease. The data concluded that more than one fourth of elderly members did physical activity. The analysis of data on difficulty in seeking proper health care for elderly revealed that 44.36 percent of elderly mentioned difficulty in health care and 55.64 percent have not faced any difficulty. Low status elderly members face more difficulty as compared to medium and high status. The public health care system is inadequate in quality as well as in quantity. Near about two fifth elderly are dissatisfied from current health care system. Data also shows elderly members prefer allopathic treatment. The main reason of preferring allopathic is fast recovery and easy availability.

An assessment of data revealed that in the case of health expenses one half of the elderly people were dependent upon their family members, spent their own saving, and took loans for treatment and elderly members use their health insurance. Regarding the household elderly health care, most of elderly people were attended by their spouse and sons. Regarding the daily health care most of household are cared by their spouse (40.29 percent and son/daughter in law (35.97 percent). The analysis of data on main causes of diseases revealed that one-fourth of household heads mentioned old age, followed by the God's curse, and germs the main reasons. Further, it came to light that the high status households mentioned scientific reasons, i.e., one-third of them reported ageing as the main reason and one-forth termed the germs as the reason. In the low status households, the main cause of diseases was the God's curse and the poor nutritional level. In the medium status households, one-half of household heads mention the main causes were the God's curse, the germs and the ageing. A very small proportion of household heads mentioned other causes which included the religious cause as major cause of diseases.

In the case of minor diseases, one-fifth of sampled urban households preferred to seek medical treatment and more than four-fifth of elderly got no treatment. The minor diseases were the body pain, headache, toothache, giddiness, etc. However, in the high status households, more than one-fourth elderly members preferred to get treatment. But, in the low and the medium status households, this proportion was very low. Regarding the major symptoms/diseases, more than four-fifth of household heads preferred to seek treatment. In the high status households, 100 percent household heads got treatment for major symptoms, 92.92 percent in the medium status and 79.61 percent in the low status households. In this way data conclude people preferred treatment for major symptoms of diseases. They always ignored the minor symptoms of any diseases as they preferred home medicine to treat minor symptoms of any diseases

The main reasons for not taking treatment for minor diseases prefer home medicine, costly treatment and loss of working days. The data on households preferring treatment revealed that more than threefifth got treatment from the MBBS/MD doctors. In the case of high status households most of elderly preferred treatment from the doctors having MBBS/MD degree compared to the medium status households and the low status households. Indeed, it is major worry that in the low status households, majority of patients got treatment from the unqualified healers.

With regard to the reasons behind seeking treatment from a particular doctor/centre, the analysis of answers given by the household heads presented interesting facts. For instance, on the whole, onefourth of households preferred treatment from experienced doctor/centre; one fifth households 
mentioned the fast recovery as the reason, one fourth of elderly were attracted due to good facility available in the centre/doctor; near about three-fifth of households preferred it due to not costly treatment and the centre/doctor which was near to home.

\section{References:}

1) Priyanka, and Mishra, S. (2010), 'Gender Difference in Life Satisfaction of Elderly People'. An International Journal Advance Research Journal of Social Science. Vol. 1, No. 2., pp. 176-179.

2) World Health Organization, (2013), Towards Policy for Health and Ageing. [Last accessed on 2013 May 22]. Available from:http://www.who.int/ageing/publications/alc fs_ageing_policy.pdf.

3) Kaur, J., (2018), 'Ageing Diseases and Health Care Providers: A Study of Elderly in Urban Punjab', Up Coming Ph.D. Thesis, Department of Economics, Punjabi University, Patiala.

4) Gururaj, Maheshwaran, (2014), 'Kuppuswamỳ's Socio-Economic Status Scale -A Revision of Income Parameter For 2014', International Journal of Recent Trends in Science and Technology, ISSN 2277-2812 E-ISSN 22498109, Vol.11, No.1, pp. 01-02.

5) Raveendran, G., Kannan, K. P., and Sengupta, A. (2008), 'India's Common People: Who Are They, How Many Are They and How Do They Live?' Economic and Political Weekly, Vol.43, No.11.

6) Brunner, E. (2005), 'More Evidence that a Healthy Lifestyle Matters: Converting Epidemiology to Policy,' Evidence-Based Healthcare \& Public Health, Vol. 9, No. 2, pp. 108-10.

7) Nelson, M. E., Rejeski, W. J., Blair, S. N., Duncan, P. W., Judge, J. O., King, A. C., ...Castaneda-Sceppa, C. (2007). Physical activity and public health in older adults: Recommendation from the American College of Sports Medicine and the American Heart Association.Circulation, 116 (9), 1094-1105.

8) Parker, B., Thomposon, P.D., and Gregory, S.M. (2012), 'Physical Activity, Cognitive Function, and Brain Health: What Is the Role of Exercise
Training in the Prevention of Dementia?' Brain Sci. Dec, Vol. 2, No.4, pp.684-708.

9) Lautenschlager, N.T., Cox, K.L., and Flicker, L.,(2008), 'Effect of Physical Activity on Cognitive Function in Older Adults at Risk for Alzheimer Disease: A Randomized Trial'. JAMA, Vol. 300, No. pp.91027-1037.

10) Lee, Y., Kim, J. H., Lee, K.J., Han, G., Kim, J. L.(2005), 'Association of Cognitive Status with Functional Limitation and Disability in Older Adults', Ageing Clin Exp Res. Vol. 17, pp.2028.

11) W.H.O. Joint Report/F.A.O. Expert Consultation, (2004), 'Diet, Nutrition and the Prevention of Chronic Disease'.

12) WHO (2005), Preventing Chronic Diseases: A Vital Investment, WHO Press, Geneva (Switzerland).

13) Chang, T.P. (1992), 'Implication of Changing Family Structure on Old Age Support in the ESCAP Region, Asia Pacific Population Journal Vol.7, No.2, pp. 49-66.

14) Grosh, M. and P. Glewwe, (2000), 'Designing Household Survey Questionnaire for Developing Countries' Lesson from 15 years of Living Standard Measurement Study ,Vol.1, Washington , D.C World Bank.

15) Silva, I. D. (2005), 'Family Transition in South Asia: Provision of Social Services and Social Protection', Asia Pacific Population Journal, Vol. 20, pp.15-45.

16) Bose, A. M. (2007), 'Health Care Provider Choice and Utilization among the Elderly in A State in Brazil: A Structural Model', Pan American Journal of Public Health, Vol. 22, No.1, pp. 4150.

17) Logan, R.L., Scott, P.J., (1996), 'Uncertainty in Clinical Practice: Implications for Quality and Costs of Health Care'. Lancet, Mar 2, Vol. 347, No. 9001, pp.595-98.

18) Reji, R.K. and Kaur, S. (2015), Prevalence of Common Physical Health Problems among Elderly in Selected Old Age Homes of a Cosmopolitan City, Indian Journal of Science and Research, Vol. 4, No. 6, June. 